\title{
INVESTIGACIÓN
}

Recibido: 28/06/2020 --- Aceptado: 29/07/2019 --- Publicado: 15/09/2020

\section{PARA COMPRENDER LA POLÍTICA DIGITAL - PRINCIPIOS Y ACCIONES}

\author{
Understanding Digital Politics - Basics and Actions
}

(D) Geresa Piñeiro-Otero'. Universidade da Coruña. España. teresa.pineiro@udc.gal

Xabier Martínez Rolán. Universidade de Vigo. España. xabier.rolan@uvigo.gal

\section{RESUMEN}

La irrupción de internet ha obligado a una reformulación de la comunicación en todos los ámbitos y a todos los niveles. Políticos y candidatos se han visto obligados a adaptarse a un medio en constante cambio, donde las reglas de la comunicación unidireccional se pierden, pero las posibilidades técnicas y el alcance de los mensajes se multiplican. Este artículo realiza efectuar una aproximación a las herramientas y prácticas de la tecnopolítica así como el uso táctico y estratégico de las herramientas digitales para la organización, la comunicación y la acción. Para ello, señala las principales plataformas ligadas a internet como web, redes sociales, las plataformas de mensajería instantánea y, más recientemente, las aplicaciones para smartphone de uso exclusivamente político. Asimismo, se analizan las tendencias actuales ligadas a la celebrificación del candidato, el uso de memes, las etiquetas como elemento vertebrador y transversal en la comunicación digital, el análisis de big data como la última frontera y la participación a través de usuarios (semi)automatizados o bots. Desde el punto de vista del ruido comunicativo, se abordan dos de las principales problemáticas de la comunicación política como son el astroturfing - en todas su variantes - y las fake news, ligadas al creciente discurso de odio en plataformas digitales. Finalmente, y tras el análisis realizado, se propone lo que, a juicio de los autores, son las claves para entender la política que está por venir.

PALABRAS CLAVE: Comunicación política - internet - redes sociales - marketing político - ciberpolítica - política digital - tecnopolítica.

\footnotetext{
1 Teresa Piñeiro Otero: Licenciada en Publicidad y Relaciones Públicas y Doctora en Comunicación por la Universidade de Vigo. Profesora del Departamento de Sociología y Ciencias de la Comunicación de la Universidade da Coruña.
} 


\author{
Piñeiro-Otero, T. y Martínez Rolán, X. \\ Para comprender la política digital - principios y acciones
}

\begin{abstract}
The emergence of the Internet has forced a reformulation of communication in all areas and at all levels. Politicians and candidates have been forced to adapt to a constantly changing environment, where the rules of one-way communication are lost, but the technical possibilities and scope of the messages are multiplied. This article makes an approach to the tools and practices of technopolitics as well as the tactical and strategic use of digital tools for organization, communication and action. To this end, it highlights the main platforms linked to the internet such as websites, social networks, instant messaging platforms and, more recently, smartphone applications for only political use. It also analyses the current trends linked to the celebration of the candidate, the use of memes, hashtags as a vertebral and transversal element in digital communication, the analysis of big data as the last frontier and the participation through (semi-)automated users or bots. From the point of view of communicative noise, two of the main problems of political communication are addressed, namely astroturfing - in all its variants - and fake news, linked to the growing discourse of hate on digital platforms. Finally, and after the analysis carried out, it is proposed what, in the opinion of the authors, are the keys to understanding the politics that are to come.
\end{abstract}

KEYWORDS: Political communication - internet - social networks - political marketing - cyberpolitics - digital politics - technopolitics.

\title{
PARA ENTENDER A POLÍTICA DIGITAL - PRINCIPIOS E AÇOES
}

\section{RESUMO}

A irrupção da internet forçou uma reformulação da comunicação em todos os âmbitos e em todos os níveis. Políticos e candidatos foram forçados a se adaptar a constantes mudanças, onde as regras da comunicação unidireccional se perdem, mas as possibilidades técnicas e a abrangência da mensagem se multiplica. Este artigo procura efetuar uma aproximação as ferramentas e práticas da tecnopolítica assim como também o uso tático e estratégico das ferramentas digitais para a organização, a comunicação e a ação. Para isto, indica as principais plataformas ligadas a internet como web, redes sociais, as plataformas de mensagens instantâneas e, mais recentemente, os aplicativos para smartphone de uso exclusivamente político. Da mesma forma, se analisam as tendências atuais ligadas a celebrificação do candidato, o uso de memes, as etiquetas como elemento vertebrador e transversal na comunicação digital, a análise de big data como a última fronteira e a participação através de usuarios (semi)automatizados ou bots. Do ponto de vista do ruído comunicativo, se abordam dois das principais problemáticas da comunicação política como são o astroturfing - em todas suas variantes - e as fake news, ligadas ao crescente discurso de ódio nas plataformas digitais. Finalmente, e após a análise realizada, 
propõe-se quais são, na opinião dos autores, as chaves para entender a política que está por vir.

PALAVRAS CHAVE: Comunicação política - internet - redes sociais - marketing político - ciberpolítica - política digital - tecnopolítica.

\section{Como citar el artículo:}

Piñeiro-Otero, T. y Martínez Rolán, X. (2020). Para comprender la política digital principios y acciones. [Understanding digital politics-basics and actions]. Vivat Academia. Revista de Comunicación, 152, 19-48. doi: http://doi.org/10.15178/va.2020.152.19-48 Recuperado de http:// www.vivatacademia.net/index.php/vivat/article/view/1251

\section{INTRODUCCIÓN}

El medio digital ha favorecido una profunda transformación tanto en el modo de entender la política como en sus manifestaciones. A lo largo del siglo XXI las acciones y comunicación política se ha desligado de las instituciones para conformar un entorno complejo de convergencia de viejos y nuevos medios, de acciones institucionales y sociales, donde los agentes políticos clásicos y ciudadanía convergen de múltiples formas (Boulianne, 2009; Rueda Ortiz, 2009; Jenkins, 2006). En Internet la comunicación política se ha redimensionado, lo que ha llevado a la aparición de nuevas formas políticas no institucionales y la irrupción de una red interconectada de usuarios -más o menos distribuida- (Martínez-Rolán y Piñeiro-Otero, 2017; Smith et al., 2014).

En este contexto la multiplicación de canales y fórmulas de comunicación ha dado lugar a una nueva ecología mediática (Islas, 2015), en la que los actores clásicos (partidos, líderes políticos y medios de comunicación) han perdido la exclusividad de la comunicación política.as redes sociales han demostrado ser más influyentes para la movilización social que otros medios convencionales, gracias a su interactividad e inmediatez, permitiendo que el diálogo se democratice y mutiplique (Hernando y Paramio, 2019). En Internet cada nodo de estas redes puede erigirse como emisor, lo que ha llevado a la irrupción de una autocomunicación de masas (Castells, 2009 y 2011).

Más allá de perspectivas utópicas, que confieren las mismas oportunidades y poder a todas las personas usuarias para erigirse como emisoras, la realidad es que la relevancia de un usuario en Internet va a depender de los nodos de su red, de las interacciones que establece y su estructura (Martínez-Rolán y Piñeiro-Otero, 2017). Pese a que en la arena virtual las relaciones son masivas y tienden a permanecer invisibles (Del-Fresno-García, 2014), cada nodo presenta un valor diferente. Este nuevo capital social es, siguiendo a Zúñiga et al. (2017) específico de la esfera online, aunque, en ocasiones, viene heredado de la arena "real". Así, el análisis de la 
conversación política 2.0 revela la irrupción de nuevos emisores y relaciones de poder, pero también el importante peso que continúan detentando los agentes políticos clásicos hasta el punto de situarse en un punto central en torno al que orbitan diversos tipos de usuarios.

La accesibilidad de la Red, tanto desde la perspectiva de la emisión como de la recepción de mensajes, ha hecho realidad la idea de automediación: entidades, personalidades y colectividades han hecho de Internet y de las plataformas sociales un espacio para la difusión de sus acciones y contenidos, que le ha permitido un canal directo con sus diferentes públicos y atañentes, soslayando la injerencia de los medios de comunicación (Piñeiro-Otero y Martínez-Rolán, 2019). Esta automediación ha pasado de constituir un complemento a los canales tradicionales para ocupar un espacio central en la comunicación pública de los agentes políticos (López-Meri et al., 2017).

En un momento en que la política está orientada hacia su mediatización (Enguix Oliver, 2015), partidos, líderes e instituciones aprovechan las ventajas comunicativas de social media y otras plataformas online para llegar directamente a los públicos, incluso cuando han de comunicar acciones y decisiones clave (Gallardo-Paúls y Enguix, 2016). Además de la reedición de procesos de dosificación informativa con los que los políticos tratan de marcar la agenda mediática (Enguix Oliver, 2015) o eludir su infrarrepresentación (Piñeiro-Otero y Martínez-Rolán, 2019), líderes como Barack Obama (con el comunicado para presentarse a la reelección en 2012), Peña Nieto (cuando, como cabeza del Gobierno Mexicano, anunció la captura del narcotraficante "El Chapo Guzmán") y, sobre todo, Donald Trump y sus prácticas comunicativas diarias, han convertido a Twitter en una suerte de agencias de noticias.

Sea como fuere, la creciente entidad de lo virtual en el día a día de la ciudadanía ha llevado a partidos y personalidades políticas a desarrollar una estrategia comunicativa activa en Internet. El traspaso a un entorno interactivo ha exigido reformular la comunicación atendiendo a las singularidades y especificidades de los canales 2.0 para una mayor eficacia y participación de los usuarios. Hoy no tiene sentido que los agentes políticos continúen empleando las plataformas y servicios de la web social con una lógica 1.0, como meros altavoces de un discurso vertical sin tener en cuenta la respuesta de los usuarios (Caldevilla, 2009).

El salto a los social media facilita la proximidad con la ciudadanía además de igualar grandes fuerzas políticas con aquellas minoritarias, o no consolidadas, debido a una menor demanda de recursos y la ausencia de filtros impuestos por los media convencionales (Padró-Solanet y Carenal, 2008). Un ejemplo de ello lo encontramos en la comunicación de Podemos (Peris Vidal, 2008).

Inmersos en la "tercera edad" de la comunicación política (Blumler y Kavanagh, 2010), el marketing político -entendido como un ensamble de teorías y métodos instrumentales destinados a una eficiente mediación entre el agente político y la

Vivat Academia. Revista de Comunicación. 15 septiembre / 15 diciembre 2020, nº 152, 19-48 
ciudadanía (Rey Lenon, 1995)- se centra, cada vez más, en las plataformas online, dado su carácter directo, abierto, masivo e interactivo, su capacidad viral, y sus posibilidades para la medición de resultados, que facilita a los agentes políticos un mayor conocimiento de sus votantes potenciales al tiempo que genera en la ciudadanía una sensación de proximidad que les lleva a interactuar con los perfiles políticos aún sin esperar respuesta.

En un momento en el que el marketing político ha puesto su foco en la construcción de las personalidades políticas como marcas Internet brinda múltiples herramientas y oportunidades para lograr su posicionamiento en un espacio ideológico cada vez más difuso, así como en la mente de sus públicos y posibles electores (Winther, 2017). Fenómenos característicos de la política actual, como la fragmentación del discurso (Hallin, 1992), la personalización de la política (Mazzoleni y Schulz, 1999) o su progresivo acercamiento hacia fórmulas, temas y géneros de entretenimiento (Blumler y Kavanagh, 1999; Berrocal Gonzalo, 2015) han logrado en la Red su máxima expresión. Solamente resulta preciso acceder a los perfiles en redes sociales de partidos y personalidades políticas para observar cómo sus ideas fuerza se balcanizan en múltiples mensajes, de carácter multimodal (texto, imágenes, vídeo, audio...), cuidadosamente diseñados-producidos que, además de las acciones y reflexiones de las personalidades políticas en su rol de candidatas o integrantes de instituciones, muestran retazos de su vida diaria como ciudadanas, familiares o amigas.

Paradójicamente, al tiempo que las redes sociales han incorporado los aspectos más humanos y cotidianos de estas personalidades se ha producido una profesionalización de la comunicación en estas plataformas, de modo que lo que la ciudadanía considera "personal" o "casual" supone el resultado de una estrategia cuidadosamente diseñada y gestionada por el equipo del líder aún con "injerencias" de éste.

Internet, así como sus diferentes plataformas y servicios, detentan una lógica propia que se sustenta en normas y prácticas comunicativas específicas (Van Dijck y Poell, 2013) como el poder de los algoritmos como gatekeepers de la información digital, la importancia de los contenidos para lograr el compromiso de los usuarios de cara a su mayor expansión y el desarrollo de procesos de influencia social, o una cultura de adhesión que prima la ratificación sobre la deliberación (de Aguilera y Casero-Ripollés, 2018).

\section{OBJETIVOS}

En los últimos años los estudios en torno al marketing político se han articulado, siguiendo a Negro (2016) en torno a tres ejes: los líderes y partidos políticos como marcas, el papel de los medios de comunicación y las estrategias empleadas en su construcción (Cfr. Guzman et al., 2014; Zavattaro. 2010; Parker, 2012; o Saftoiu y Popescu, 2014.). Estas tres perspectivas van a interactuar a diferentes niveles en el ámbito de las plataformas digitales. 
La comunicación electoral y presidencial de Barack Obama se ha adelantado y/o ha llevado a su máxima expresión, el empleo estratégico de la hipersegmentación de públicos, el uso de memes (para Rodríguez, 2013, Obama es el memécrata por excelencia), APPs, el uso creativo de redes sociales como Facebook y Myspace, la creación de una web específica para contrarrestar difamaciones, y la capacidad -y acierto- en la adaptación de los mensajes de su campaña a plataformas tan diferentes como mensajería instantánea, blogs, Youtube o una televisión online, con objetivos tan diversos como la comunicación, la movilización ciudadana o la recaudación de fondos, que una década después es emulado por personalidades políticas de todo el mundo (Cfr. Bimber, 2014; Miller, 2013; Castro Martínez, 2012; Hedges, 2010 ó Zavattaro, 2010, entre otros).

La orientación de las estrategias políticas a las plataformas y servicios online han propiciado nuevas reflexiones sobre este tipo de comunicación y sobre la gestión de la imagen de partidos y personalidades en entorno digital (Paré y Berger, 2008, Marland, 2012).

Para Avalos González (2019), estos usos estratégicos de las tecnologías comunicativas trascienden la idea de la tecnología como herramienta para dotarlas de un significado como dispositivos para la acción que se encuentran entrelazados con procesos de subjetividad diferenciados según las condiciones contextuales de los agentes políticos.

En este sentido el objeto del presente trabajo es el de efectuar una aproximación a las herramientas y prácticas de la tecnopolítica, entendida como el movimiento de renovación política a través de la tecnología social (Gutiérrez-Rubí, 2014) así como el uso táctico y estratégico de las herramientas digitales para la organización, la comunicación y la acción (Toret, 2015). Aunque este término suele emplearse para hacer referencia a las prácticas online de grupos de oposición y movimientos sociales (Avalos González, 2019; Treré y Barranquero, 2018), en este texto lo utilizaremos para incidir únicamente en la transformación de los procesos y espacios para la comunicación de los agentes políticos clásicos, como sinónimo de política 2.0 o de ciberpolítica que, aún con sus matices, aluden a otra forma de entender las relaciones entre gobernantes y gobernado (Kruikemeier, 2014; Matud-Juristo, 2009) en espacios virtuales que comenzaron siendo una extensión de la esfera pública (Westling, 2007) pero que, cada vez más, se sitúan en un lugar relevante de ésta.

Las estrategias desarrolladas en estas plataformas se pueden vincular a conceptos como segmentación, personalización y engagement (Fernández Quijada y Ramos Serrano, 2014) así como a la idea de campaña permanente (Loomis, 2004; Needham, 2005). Si el marketing político tiene su máxima expresión en el marketing electoral (Lindon, 1976), en el ámbito de Internet se desdibujan las fronteras entre ambas e incluso con la comunicación institucional, de modo que resulta complejo determinar dónde empieza-termina la comunicación de partido y donde lo hace la del gobierno. 
Piñeiro-Otero, T. y Martínez Rolán, X.

Para comprender la política digital - principios y acciones

\section{PLATAFORMAS}

La tecnología que da soporte a la transmisión de datos entre computadoras ha cambiado mucho a lo largo de los años y permite diferente canales y plataformas. A pesar de la multitud de protocolos existentes, algunos sobreviven realizando las mismas funciones que antaño - como el smtp para el correo o ftp para transferencia de archivos, ninguno ha sito tan prolífico como el http/s sobre el que se ejecutan web y redes sociales. He aquí algunas de las principales plataformas de la ciberpolítica.

\subsection{Web}

La invención y popularización de la web en la década de 1990 también ha afectado a las organizaciones políticas y a la forma de hacer política. Desde sus inicios, los políticos han buscado su propio espacio en la web. Ya en 1992 Bill Clinton empleó la red para buscar el apoyo del electorado (Kiyohara et al., 2017, p.173) y la participación política en forma de espacio web evolucionó desde pequeños espacios virtuales con la información equivalente a una tarjeta de visita virtual hasta las complejas salas de prensa, espacios privados para afiliados y repositorio de contenidos textuales y audiovisuales actuales.

El portal web se erige, precisamente, como portal de la política digital. Es el punto de encuentro digital y a donde se deriva tráfico desde las redes sociales, aunque como fuente partidaria no gozará de tan buena reputación como los medios de comunicación, entre otras cosas porque, como señalan Serra y Gonçalves (2016) el nivel de participación que proporcionan los sitios web de los partidos políticos a los ciudadanos atiende más a cuestiones propagandísticas o persuasivas que a una verdadera participación.

Es posición ciberpesimista (Coleman, 2001) choca frontalmente con otros autores más optimistas que destacan las herramientas y sus posibilidades en los sitios web para la reformulación de políticas públicas, como es el caso de Norris, cuando apunta que el sitio web no es una mera fórmula de comunicación unidireccional.

these websites are not simply 'top-down' channels of information, or party propaganda, instead, contrary to the American studies, in Europe they also facilitate 'bottom-up' communication from citizens to parties and elected officials. The content analysis showed that party websites contained many features that could potentially strengthen the relationship between supporters and leaders, providing opportunities for feedback and input into the policy process as well as the mobilization of support (Norris, 2003, p.43).

Una ventaja de los sitios web con respecto a las redes sociales es su popularidad entre diferentes franjas de edad. Mientras las primeras son el eje central de la información en las generaciones más jóvenes, el factor de reconocimiento y uso de la web se mantiene estable en todos los grupos etarios.

Vivat Academia. Revista de Comunicación. 15 septiembre / 15 diciembre 2020, nº 152, 19-48 
Piñeiro-Otero, T. y Martínez Rolán, X.

Para comprender la política digital - principios y acciones

\subsection{Social Media}

El desarrollo de una web más ágil y dinámica que se nutre de los postulados de O'Reilly (2004) es la antesala de los espacios de conversación digital más extendidos en la actualidad: las plataformas de gestión de redes sociales o, simplemente, social media.

Una de las principales bazas de este tipo de plataforma es su gran poder de configuración de la opinión pública. En este sentido, Twitter se ha configurado como un canal fundamental para la comunicación política 2.0 (Ruiz-del-Olmo y BustosDíaz, 2016). Esto se debe a varios factores, como la naturaleza pública y asimetría de las relaciones (no es necesario estar registrado para acceder a los contenidos, ni es necesario que te sigan para seguir a otros), la brevedad de sus mensajes (hasta un máximo de 280 caracteres) y un factor expansivo entre medios de comunicación que aumentan considerablemente su visibilidad.

La elevada politización de la plataforma permite acudir a ella como un termómetro de la opinión pública (Barberá y Rivero, 2012; Kruikemeier, 2014; PeñaLópez, Congosto y Aragón, 2014; Martínez-Rolán y Piñeiro-Otero, 2016), aunque pueda deformar la realidad por sus sesgos y configuración de las agrupaciones de usuarios (Martínez-Rolán y Piñeiro-Otero, 2017).

Es por ello por lo que Twitter, desde sus orígenes, haya suscitado el interés de la Academia, con numerosas aproximaciones, en su mayoría de carácter cuantitativo debido a la facilidad de acceder a los datos a través de la API pública.

Este enfoque ha orientado tanto los estudios pioneros en dicha plataforma (Java et al., 2007; Krishnamurthy et al., 2008; Huberman et al., 2009), como los análisis cibermétricos (Azorín-Richarte, 2012) o las clasificaciones de comunidades en la tweetesfera de Smith et al. (2014) que constituyen la base de este trabajo. Si bien es cierto que el debate político no es el objeto principal de Twittter, autores como Calatrava (2015) apuntan la idoneidad de esta plataforma para movilizar al público cautivo de cada partido y tratar de pescar en el caladero de los indecisos). De hecho, la propia red de microblogging se etiqueta a sí misma como la mayor plataforma online de influencia política en España (Calatrava, 2016).

Con todo, la política 2.0 no es solo Twitter. Facebook, pese a ser un jardín vallado (Dans, 2012), es el lugar que aglutina a un mayor número de usuarios en casi todos los países del mundo. De hecho, es tal la microsegmentación que permite esta red social (ver el apartado de big data) que ha llevado a la publicidad en plataformas sociales a otro nivel, con escándalos de gran envergadura ligados a la política como la cosecha de los datos de 50 millones de perfiles en esta red social, poniendo en duda la privacidad de la plataforma y el papel del uso de datos por parte de terceros (Isaak y Hanna, 2018). 
El viraje hacia una web más visual ha destacado el papel de nuevas plataformas de éxito, como es el caso de Instagram o TikTok.

En el caso de Instagram, que en la segunda mitad de la década de 2010 se ha convertido en la red favorita de los jóvenes, la apropiación por parte de los políticos comenzó de forma tímida y sin una estrategia de contenidos clara, pero que ahora mismo es clave en la forma en la que las imágenes y textos de las publicaciones llegan a nuevas audiencias que, a priori, podrían no estar interesadas en política. (Selva-Ruiz y Caro-Castaño, 2017; Lalancette y Raynauld, 2019). Con todo, y desde la academia, es necesario profundizar en la comprensión del relato político a través de este tipo de plataformas visuales.

En segundo lugar, la red social de microvídeos TikTok que permite subir vídeos de hasta un minuto de duración, cargando piezas de elevada complejidad creativa o simples clips de vídeo con un texto sobre un fondo de color. A diferencia de otras redes sociales, el aspecto musical cobra más relevancia, convirtiéndose en muchos casos en el eje del mensaje o en el factor memético que hace crecer la viralidad de la publicación. Aunque aún es pronto para que la Academia puede analizar pausadamente sus efectos, Serrano et al. (2020) señalan que el contenido político parece ser un aspecto relevante del ecosistema de TikTok, por lo que resultará conveniente analizar el sistema de recomendaciones de la plataforma para constatar si se trata de un escenario imparcial para la comunicación política 2.0 o no.

La configuración de estos espacios virtuales ha permitido la evolución de la figura de los especialistas o recomendadores, ahora conocidos como influencers. En esta situación, los protagonistas que conectan de forma especial con los usuarios se ven magnificados por una enorme tasa de aplauso y una influencia que puede llegar a trascender las fronteras de la red social, y que entronca con la celebrificación del candidato (ver apartado en este texto)

Al margen de las propias plataformas, cuyo valor reside en los contenidos que vuelcan sus usuarios, cobra también importancia el buscador interno y su optimización. De hecho, la red social de vídeos YouTube es el segundo motor de búsquedas más empleado del mundo, tan solo superado por su propietaria, Google, lo que redunda en la importancia este tipo de plataformas

\subsection{Mensajería instantánea}

La exposición pública a la que se someten los usuarios a través de redes sociales es un factor determinante par emplear soluciones de comunicación más privada, más oscura, aunque igual de efectiva. Así, la mensajería instantánea se alza como uno de los servicios más empleados en los smartphones. Un servicio liderado por WhatsApp (Facebook) en casi todos los países del mundo, junto con otras aplicaciones como Messenger (Facebook) o Telegram. De hecho, todas las plataformas de gestión de redes sociales cuentan con su propia funcionalidad de mensajería instantánea de forma privada. 
Al igual que sucedió con los social media, si los usuarios comenzaron a emplear estas herramientas para comunicarse, más oscuras y ocultas al tráfico trazable de la red (es por ello por lo que, en analítica web, se conoce al tráfico de mensajería instantánea como "dark social"), entonces los partidos también se animarán a emplearlas.

De acuerdo con Valeriani y Vaccari (2018), la mensajería instantánea se están convirtiendo en una arena relevante para la conversación política digital, aunque, como también apuntan, al discutir la política en entornos privados y selectivos, los usuarios de estas plataformas podrían quedar atrapados en pequeñas burbujas políticas de vínculos fuertes de ideas afines - cuestión que definió Parisier (2011) como "filtro burbuja" - y quizás con opiniones políticas más polarizadas que en social media.

Esta cuestión ofrece contexto para entender cómo WhatsApp, la reina de este segmento, ha tenido que restringir el reenvío de mensajes dentro de su plataforma para tratar de frenar la desinformación y otras malas prácticas de comunicación política

\subsection{PoliticAPPS}

En un momento en que smartphones multiplican su presencia, de forma permanente, en las manos y bolsillos de millones de personas en todo el mundo (con una penetración mundial del $67 \%$ y del 116\% en España, We are social, 2020), la comunicación política se ha lanzado a la conquista de los dispositivos móviles para su comunicación estratégica. Hoy las APPs políticas constituyen la manifestación más visible de la llamada política móvil entendida como la transformación de las estructuras de partido y la acción política a entornos digitales móviles (GutiérrezRubí, 2011) y en la que se engloban manifestaciones como códigos QR, geolocalización, realidad aumentada o sistemas de mensajería instantánea desde el SMS al WhatsApp (Vázquez-Sande, 2016).

El carácter conectado y multimedia de estos dispositivos portátiles de altas prestaciones, así como la heterogeneidad de personas usuarias, incrementa la diversidad de aplicaciones que van de simples accesos directos a la página web del partido/candidato a manifestaciones más complejas que conjugan geolocalización y realidad aumentada para experiencias informativas o de entretenimiento.

Siguiendo a Gutiérrez-Rubí (2015) la facilidad de descarga de estas APPs en los dispositivos personales, así como la familiaridad de su acceso, las convierten en el paradigma de una nueva generación. De hecho, Zamora-Medina et al. (2020) subrayan la diversidad y empleo de estas APPs atendiendo a su agente promotor, objeto de la APP, nivel de interacción, autonomía o al tono predominante.

Vivat Academia. Revista de Comunicación. 15 septiembre / 15 diciembre 2020, nº 152, 19-48 
La apertura de sus dispositivos personales por parte de los usuarios permite una comunicación más individual y cercana, además de continua a través de posibles notificaciones, asimismo brinda a los partidos datos relevantes de sus posibles electores tanto de forma activa -datos aportados por los usuarios en su suscripción, así como a través de los permisos de acceso a los contactos- como de forma pasiva, a través de sus costumbres de uso. Unos datos que serán de gran utilidad para estrategias de big data.

\section{TENDENCIAS}

\subsection{Celebrificación del candidato}

Tradicionalmente el producto político constituía el resultado del trinomio: imagen del partido, del líder, más compromisos políticos (Wring, 1997). Esta mezcla ha ido escorándose, cada vez más, a la imagen del líder y/o candidato político.

La personalización de la política actual, atribuida a la americanización y presidencialización de las instituciones políticas (Norris, 2004; Cervi y Roca, 2017), ha llevado a la construcción de líderes carismáticos y mediatizables en detrimento de la renovación de ideas (Rey Lenon, 1995; Criado y Martínez Fuentes, 2010).

Si a principios de los 90 Justel (1992) advertía del lugar prominente que estaban alcanzado los candidatos políticos para la atracción de apoyos y respaldo electoral, la brandificación de las personalidades políticas constituye una práctica habitual del marketing político que adquiere particular relevancia en el ámbito online.

La personalización y popularización de la política ha propiciado la celebrificación de su comunicación, entendida como el empleo estratégico de elementos de la cultura de la fama para la construcción de la imagen de una personalidad política (Oliva et al., 2015, van Zoonen, 2006). Esta tendencia establece un vínculo entre la noción de celebridad y los atributos de poder, así como una reflexión en torno a la necesidad que tienen las personas de reconocer, en los personajes públicos, una proyección de sus propias inquietudes y deseos (Séguéla, 1991, Marshall, 1997).

Para Oliva et al. (2015, p.4) la celebrificación del candidato se sustenta en dos aspectos:

Un valor estratégico primario en tanto la incorporación de elementos de la cultura de la fama en la construcción del "candidato ideal" que permite reforzar y redefinir rasgos que contribuirán a su "gancho" mediático y "un valor estratégico secundario dado que amplía los espacios de construcción de la imagen del candidato, diversificando las vías o recursos para la caracterización del político como el candidato ideal o para reforzar su posicionamiento simbólico"

Las personalidades políticas trascienden de los medios, soportes y formatos convencionales de la comunicación política para adentrarse e incluso dominar

Vivat Academia. Revista de Comunicación. 15 septiembre / 15 diciembre 2020, nº 152, 19-48 
nuevos canales y contenidos, que les permiten presentar una imagen más informal y personal, mostrando estratégicamente sus virtudes y defectos. Las personalidades políticas "gestionan" sus canales en la Red en los que complementan su actividad política con contenidos aparentemente casuales de su vida privada, o de lo que sucede tras las bambalinas, y que los muestra como personas corrientes. El beso al bebé en los actos políticos ha dado paso a instantáneas de parentalidad, de intimidad doméstica o de actividades personales/sociales como paseos o prácticas deportivas.

Las estrategias de celebrificación en redes sociales buscan la empatía de la ciudadanía mostrando a los líderes como celebridades próximas, humanas, pero sobre todo con aptitudes para gobernar. (Quevedo-Redondo y Portalés-Oliva, 2017).

\subsection{Memes}

Probablemente uno de los fenómenos más reseñables de la Red como inteligencia colectiva (Levy, 2004) colectiva son los memes. Con este término se suele hacer referencia a imágenes de corte humorístico o satírico, habitualmente sin emisor conocido, que se expanden por la Red, difundidas y/o adaptadas por la comunidad usuaria. No obstante, el término meme hace referencia a cualquier unidad mínima de información cultural transferida entre individuos a través de procesos de replicación o transmisión (Dawkins, 2006). Esta definición que incluye imágenes, vídeos, temas musicales o incluso hashtags, contribuye a explicar la irrupción, expansión y desaparición de ideas en la Red (Santibañez, 2011). La capacidad de los memes de sintetizar una idea, situación o expresión compleja en un contenido breve, poderoso, que no resulte indiferente a la comunidad usuaria los dota de un gran potencial para la comunicación política (Martínez-Rolán y Piñeiro-Otero, 2017; Re, 2014). Para Gutiérrez-Rubí (2014, p.34) el poder de los memes, de la memecracia, reside en "La fuerza creativa del ARTivismo digital para el ACTivismo social".

Además de su apropiación para la movilización social el valor comunicativo de los memes ha llevado a su integración en las estrategias comunicativas de agentes políticos clásicos, así líderes y partidos políticos se han lanzado a la creación de contenidos, mayoritariamente de carácter visual, para su redifusión y apropiación por la comunidad usuaria. Imágenes que escenifican pactos políticos, de líderes con mascarilla o las reuniones de los titulares de presidencias y jefaturas de estado frente a una pantalla por causa del COVID-19 han sido estratégicamente "colocadas" por los equipos de comunicación para su difusión a través de la Red.

Asimismo, conscientes del papel de la comunidad en la difusión y la construcción de sentido de estos memes, los agentes políticos crean y difunden contenidos de fácil modificación o -incluso- que apelan a éstos a través de plataformas de uso masivo y global como 4chan o meme generator.

Dentro de los memes adquieren particular relevancia los gifs animados, en su mayoría microvídeos que -por la manipulación de la imagen o la introducción de subtítulos- van a ser apropiados por la comunidad usuaria a través de procesos de transmisión y replicación.

Vivat Academia. Revista de Comunicación. 15 septiembre / 15 diciembre 2020, nº 152, 19-48 
Estas prácticas icónicas y audiovisuales van a poner de relevancia una nueva relación de los actores políticos con la imagen, de un uso privativo a una concepción abierta a la interacción y creatividad del público, como una fórmula de aportar mayor visibilidad y proyección en la Red. El hecho de que los usuarios reaccionen positivamente ante un meme político o contribuyan a su difusión no los convierte en activistas, aunque en su acción favorezcan la creación de estructuras de conexión e interacción (Martínez-Rolán y Piñeiro-Otero, 2017; Harlow y Guo, 2014).

\subsection{Hashtags}

A pesar de que los hashtags pueden constituir memes por sí mismos, siguiendo a McKelvey y Menczer (2013), su relevancia en el ámbito de la comunicación política le ha dotado de su propia entidad, que ha llevado a Jeffares (2014) a hablar de "política de hashtags". De hecho, los hashtags y apertura de Twitter, hoy presente en otras plataformas sociales como Instagram (Cartes Barroso, 2015), la convirtieron en la red social política por antonomasia (Campos-Domínguez, 2017; Cihon y Yasseri, 2016).

Las etiquetas sociales, que aglutinan la conversación 2.0 en torno a un determinado tema, han sido aprovechadas para la estrategia online de los actores políticos, como una forma de apelar la participación de las personas usuarias en torno a temas de actualidad, issues de los partidos o incluso ideas-fuerza con el empleo de hashtags descriptivos o de carácter autorreferencial (Small, 2011). La creación de una comunidad efímera (Martínez-Rolán y Piñeiro-Otero, 2017) en torno a una etiqueta en Internet amplía su proyección en la Red, incluso a través de la confrontación, como sucede en el caso de las fuerzas radicales que han logrado de ese modo su permanencia en la conversación social. Un ejemplo de ello es el \#SpainSupportsTrump como reacción negativa a las movilizaciones en contra del racismo en Estados Unidos.

En el ámbito de la comunicación electoral estas etiquetas -habitualmente con la idea-eje de campaña- suelen integrarse en la cartelería y otro tipo de contenidos y soportes offline, como una puerta de acceso (o "rabbit hole") al universo transmedia de la campaña (D'Adamo y García Beadoux, 2014).

La conversión de los hashtags en tendencia, al aglutinar un importante volumen de tráfico en las redes sociales, permite atraer a nuevas personas usuarias a la conversación social e incluso injerir en la agenda mediática (de Aguilera y CaseroRipollés, 2018; Kim y Lee, 2007). En este sentido, líderes y fuerzas políticas también pueden aprovechar los temas tendencia para conocer el posicionamiento en torno a determinadas cuestiones de actualidad -así ha sucedido recientemente con \#MeToo o \#BlacklivesMatters- interactuar en torno a éstos para una mayor visibilidad de sus ideas y postulados, e incluso apropiarse de ellos polarizando la conversación. 


\section{Piñeiro-Otero, T. y Martínez Rolán, X. \\ Para comprender la política digital - principios y acciones}

\subsection{Big Data}

A las potencialidades de las plataformas y medios virtuales para la medición de las acciones desarrolladas en tiempo real -seguimiento, interacciones, compromiso de la comunidad, etc.- deben sumarse su oportunidad como fuentes de datos.

Una de las tendencias de la comunicación global que puede ser empleada con éxito por las instituciones y agentes políticos es la explotación de las grandes cantidades de datos textuales disponibles en la Red a través del uso masivo de las plataformas sociales y de fuentes textuales de información, como medios de comunicación online, webs oficiales o informes, entre otros (Arcila-Calderón et al., 2016; boyd y Crawford, 2012). Este fenómeno, conocido como “Big data" se refiere tanto al volumen complejo y masivo de información, que requiere métodos computacionales para extraer conocimiento, como a la intencionalidad y utilidad de este (Murphy y Barton, 2014).

El escándalo de Cambridge Analytics, consultora especializada en minería y analítica de datos para comunicación electoral, ha propiciado la asociación del Big Data con la manipulación política. Si bien la propia configuración de nuestra red social online como una "cámara de resonancia" (Mendieta y Jiménez, 2012), con ideas y pensamientos próximos, nos hace más permeables a los contenidos distribuidos en ésta, lo cierto es que se pueden señalar numerosas posibilidades del empleo estratégico del Big Data para la comunicación política.

La ONG internacional Tactical Tech (2018) señala tres usos estratégicos de la interpretación de datos para la política:

1. Como activo político, en tanto brindan información valiosa sobre la ciudadanía.

2. Como inteligencia política, dado que permiten conocer las preferencias políticas de los votantes de cara a definir estrategias y determinar prioridades de campaña.

3. Como influencia política, la recogida-análisis de datos puede emplearse para dirigirse a electorado y ciudadanía con el fin de influir sus opiniones.

Estos usos han alcanzado su máxima expresión en el ámbito de las campañas electorales. Si bien el empleo del big data en las campañas electorales detenta en Estados Unidos es anterior a la web (Bejarano, 2017), cuenta con mayor proyección en el ámbito actual dado el volumen y calidad de la información disponible, y sus posibilidades de uso. Así, una de las prácticas más conocidas del empleo de 'Big data' es la segmentación estratégica de públicos a través dl fraccionamiento del electorado en pequeños grupos atendiendo a características comunes, que pueda ser de utilidad para la planificación de mensajes-soportes (Hidalgo, 2014). Si la campaña de Bill Clinton para las presidenciales de 1996 desarrolló una planificación de medios específica para las "soccer mum" (Carroll, 1999), en 2008 el candidato Barak Obama llevó a cabo una estrategia puerta a puerta con "Moms for Obama" (González, 2010).

Vivat Academia. Revista de Comunicación. 15 septiembre / 15 diciembre 2020, nº 152, 19-48 
Las posibilidades que brindan las plataformas digitales, especialmente algunas como Facebook, para llegar a públicos muy concretos aún dispersos geográficamente ha posibilitado una microsegmentación del electorado que permite la creación de mensajes ad hoc, y que ha sido empleada con éxito en campañas como la del Referendo por el Brexit (2016), la de Trump para las elecciones presidenciales de 2016 (Grasseger, y Krogerus, 2017) e incluso en la estrategia de partidos españoles como la de Ciudadanos para las elecciones generales de 2015.

Más allá del empleo de los grandes datos para un impacto más eficiente en usuarios-electores la cantidad de información que empresas como Google tienen sobre quién somos y qué somos como sujetos sociales es tan grande que - siguiendo a Lys (2019)-pueden reconfigurar la estructura misma de las sociedades y a la política como estructura de la gobernanza social.

En el ámbito de la política el "Big data" las instituciones y partidos políticos mainstream pueden emplear técnicas de minería de datos para conocer a la ciudadanía de cara a adaptar el discurso y acciones al sentir de la mayoría (o de determinados grupos de interés), pero también puede servir a plataformas ciudadanas, activistas e incluso formaciones políticas para fiscalizar las actuaciones políticas de los Gobierno y los partidos, en una suerte de minería de datos (de Aguilera y Casero-Ripollés, 2018). A pesar de sus múltiples utilidades en política Lys (2019) señala que se debe huir de la ilusión de que los grandes datos permiten predicciones fiables, dado lo voluble de la realidad y la imposibilidad de integrar en los cálculos todos los condicionantes posibles.

\subsection{Bots}

El desarrollo de las redes sociales, mensajería instantánea y apps han supuesto un aumento exponencial de las interacciones, y el uso de las mismas ligado a servicios de atención al cliente o similar han tenido que centrar sus esfuerzos en optimizar los recursos. Muchos de estos servicios emplean mucho tiempo y recursos en responder a cuestiones muy parecidas, una suerte de FAQs que se pueden automatizar con la ayuda de asistentes virtuales o bots.

Los bots son piezas de software automatizadas o semiautomatizadas para responder a estímulos o diseminar mensajes de forma mecánica.

Desde la perspectiva de las buenas praxis el uso de bots no está muy extendido en política, aunque Gutiérrezz-Rubí (2016) apunta una interesante tipología de bots que pueden ponerse al servicio de partidos y candidatos, y no de forma inmoral. Se trata de bots de seguidores (aquellos que ayudan a aumentar el número de seguidores), bots de difusión (automatizan tuits y retuits selectivos), bots de tráfico (destinados a aumentar interacciones en contenidos), bots temporales (consiste en ceder temporal o temáticamente un usuario para una causa, a través de contenidos automatizados), chatbots automáticos (útiles para conversaciones semi-automatizadas) y bots asistentes de políticos. 
El uso de chatbots automáticos o asistentes conversacionales, en concreto, sí se ha disparado en los últimos meses, sobre todo en plataformas más amigables como es el caso de Telegram. En relación con la pandemia provocada por la Covid-19, organizaciones como la OMS o el Ministerio de Sanidad (España) han creado sendos chatbots para WhatsApp para informar en tiempo real y bajo demanda a los usuarios, para responder a dudas sobre el coronavirus, un ejemplo que se puede encontrar en muchos otros países del mundo.

\section{MALAS PRAXIS}

Las posibilidades del entorno digital en la comunicación política son, como se ha recogido a lo largo del trabajo, de gran impacto y con un largo recorrido. Con todo, y dado que, siguiendo a Kranzberg (1986) la tecnología no es buena, ni mala, ni neutral, las disfunciones de la comunicación política también son objeto de estudio por el ruido que generan.

Cuando Google estableció sus reglas para que las páginas intentasen posicionarse en el buscador (esto es, aparecer más arriba en los resultados de búsqueda para una búsqueda concreta) comenzaron a proliferar malas prácticas que buscaran un posicionamiento eficaz a través artimañas que burlaban las directrices del buscador. A es conjunto de malas praxis se le conoce como Black Hat Seo. Del mismo modo, en la ciberpolítica, también podemos hablar de Black Hat Politics entre los que destacarían el astroturfing y las fake news.

\subsection{Astroturfing}

El término astroturfing hace referencia a todo tipo de movimientos orquestados y operados desde la sombra. Es un juego de palabras entre "AstroTurf" (una marca de césped artificial muy popular en Estados Unidos, empleada como metonimia de césped artificial en general) y grassroots (raíces de hierba) que es como se conocen a los movimientos naturales y espontáneos al margen de las estructuras de poder (Martínez Rolán et al., 2015, Rodríguez-Salcedo, Gómez-Baceiredo, Tigner).

El término, acuñado en 1985, se refirió inicialmente a los actos y actividades no espontáneas integradas dentro de la estrategia de persuasión de partidos políticos, agencias de relaciones públicas o empresas.

Este concepto, que en esencia consiste en disfrazar falsas opiniones o argumentos y darle apariencia de realidad, adquiere una nueva dimensión con el surgimiento de internet $\mathrm{y}$, sobre todo, las redes sociales. La (falsa) sensación de anonimato, la facilidad para crear cuentas y publicar contenidos en plataformas sociales y la credibilidad que se da a este tipo de contenidos es el caldo de cultivo perfecto para este tipo de prácticas. 
Showalter y Fleisher (2005) hacen hincapié en el contexto del fenómeno, y culpan a la debilidad o fisuras del sistema democrático como causa de este tipo de prácticas (astroturfing y fake news). Cualquier institución, partido o personalidad pública puede empezar una campaña de acciones de movilización de forma oculta a las propias dinámicas de la red, y la dificultad para comprobar el origen y la veracidad de la información vertida solo pueden ser parte de una brecha en el sistema.

El astroturfing se desarrolla, sobre todo, en la esfera del mercado de bienes de consumo, entre diferentes marcas rivales, y en el ámbito de la política, bien sea para apoyar a un partido o candidato o para denigrar a los adversarios políticos.

Las técnicas ligadas a esta práctica se emplean tanto para ensalzar como para denigrar a un político o formación política. A través de una red de valoraciones favorables puede tratar de levantarse o mitigar una crisis reputacional, del mismo modo que comentarios desfavorables contra políticos o partidos - habitualmente adversarios o rivales en la esfera política - pueden utilizarse para menoscabar la imagen de los candidatos.

Algunas de las técnicas de astroturfing más habituales (Martínez Rolán, 2014) son:

1. Edición tendenciosa de la información en Wikipedia, que consiste en maquillar o abultar ciertos aspectos o facetas de determinadas entradas de la enciclopedia colaborativa más empleada en la red, con notables casos de escándalo (Bejerano, 2013)

2. Compra-venta de falsos testimonios: profesionalizar o dar soporte comercial a la tarea de publicar falsos comentarios, con un mercado en el que participan empresas que quieren comprar opinión públic y empresas y "opinadores" que reciben una remuneración por ello.

3. Creación de cuentas falsas en redes sociales. Pro su importante papel, se aborda esta técnica en los "bots".

4. Sockpuppeting: esta técnica, ligada a la anterior, consiste en la gestión de múltiples usuarios por parte de una misma persona, de forma que cada una de sus "marionetas" acude al rescate de la cuenta matriz o "titiritero". Es muy difícil de identificar, y a menudo salen a la luz porque el gestor se equivoca de cuenta al publicar.

5. Creación de blogs falsos: también se incluyen los blogs financiados por una institución política - generalmente a pequeños o medianos líderes de opinión, aunque con el auge de las redes sociales han perdido popularidad.

6. Front Organizations / Front Groups: organizaciones creadas o controladas por otra entidad para diseminar la información interesada facilitada por la cuenta matriz. En política, este papel suele estar asociado a las organizaciones juveniles de los partidos consolidados.

Existen otras técnicas de astroturfing, aunque de menor calado en la arena política, como la falsificación de tráfico web y posicionamiento en buscadores. 
Piñeiro-Otero, T. y Martínez Rolán, X.

Para comprender la política digital - principios y acciones

\subsection{Fake news}

Las fake news o noticias falsas se han convertido en el principal problema a la hora de conectar la información veraz con ciudadanos e instituciones. Desde que el diccionario Oxford destacara el término en 2017 como palabra del año complementando al concepto de 2016 "post-verdad"- el uso de las noticias falsas ha aumentado exponencialmente, hasta el punto de que en la actualidad también se habla de infodemia para referirse a la propagación de noticias falsas sobre la crisis derivada por la epidemia de la Covid19.

En los últimos años, procesos electorales de enorme calado como las elecciones presidenciales estadounidenses o el referéndum de Gran Bretaña, celebrados ambos en 2016, se han visto empañados por acusaciones de injerencias externas e intentos de manipulación de la opinión pública a través de redes de bots.

En el caso inglés, Bastos y Mercea (2019), identificaron una red de más de 13.000 usuarios de Twitter al servicio del argumentario pro-Brexit que pudieron influir en la toma de decisión de muchos electores. Por su parte, Howard, y Kollanyi (2016) hablan directamente de bots políticos y demostraron que buena parte de la conversación política sobre el Brexit no solo estaba polarizada, sino automatizada hasta en un $30 \%$ de la muestra analizada (tanto partidarios como detractores del Brexit).

Gorodnichenko et al. (2018) analizan ambos procesos electorales, Brexit y Presidenciales americanas, en la búsqueda de bots y noticias falsas en Twitter durante las campañas de las dos citas, y constataron la relación entre el propio sesgo de los usuarios y la probabilidad de ser impactados por un bot: la capacidad en que los bots pueden afectar a la actividad en twitter de usuarios legítimos, depende de si la información de los bots es consistente con las preferencias de los humanos, lo que entronca, de nuevo con el concepto ya introducido del filtro burbuja y la cámara de resonancia de cada usuario.

Grinberg et al. (2019), por su parte, analizaron la actividad en Twitter durante la campaña de las presidenciales estadounidenses y estiman que hasta el 7\% de las URL compartidas provenían de sitios web que comparten fake news, con un gran impacto y exposición entre la comunidad tuitera.

Un problema derivado de estas malas prácticas, las cámaras de resonancia y el filtro burbuja es el considerable aumento del discurso del odio. El aumento del racismo, sexismo, discriminación e intolerancia se plasma de forma visible - aunque se trata de la punta del iceberg - en un discurso cargado de insultos y amenazas, no siempre veladas, ante el que las plataformas de gestión de redes sociales tienen un difícil reto por delante.

Vivat Academia. Revista de Comunicación. 15 septiembre / 15 diciembre 2020, nº 152, 19-48 
Piñeiro-Otero, T. y Martínez Rolán, X.

Para comprender la política digital - principios y acciones

\section{A MODO DE CONCLUSIÓN}

Como medio para la autocomunicación de masas, las plataformas virtuales con frecuencia han sido consideradas como fórmulas de excepción para superar los filtros de los medios de comunicación convencionales igualando, de este modo, a grandes y pequeños partidos (Padró-Solanet y Carenal, 2008). No obstante, si bien la comunicación online exige menores recursos para llegar a la ciudadanía, resulta complejo imponerse a los grandes partidos dado el presupuesto y los profesionales que destinan a sus estrategias en la Red (Piñeiro-Otero y Martínez-Rolán, 2013).

Lejos de la democratización de la comunicación que prometían las TIC, los partidos y candidatos han sabido adaptarse a la ciberpolítica y establecer nuevos canales de comunicación donde difundir su mensaje que puedan proveer nuevas fórmulas y tendencias comunicativas (gifs, APPs, bots, videojuegos políticos...). Por ello, el futuro pasa por crear contenidos y entornos transmedia. El desarrollo de acciones políticas que mezclen estratégicamente plataformas y soportes on y offline permite una mayor presencia y permanencia de los mensajes políticos y sus emisores en la esfera pública. La adaptación a las posibilidades y al lenguaje-forma de cada plataforma posibilita una mayor proyección de los mensajes, así como un creciente interés de los usuarios para interactuar con éstos de múltiples formas, ampliando su alcance en la Red y los saltos entre plataformas on-offline. Esta concepción transmedia de la política no sólo permite el traspaso de usuarios de unas plataformas a otras, a través de "rabbit holes", sino que también posibilita la hipersegmentación de públicos en función de plataformas o de espacios dentro de éstas, siguiendo la tesis de nivelación de Dena (2008).

Con todo, dada la inflación actual de mensajes y estímulos comunicativos, el juego de adaptación líquida -como lo denomina Martínez Rolán (2018)- de partidos y personalidades políticas a la arena virtual no evita un menor impacto de los contenidos en la ciudadanía que, por una parte, de forma más o menos consciente desconecta de los miles de impactos comunicativos a los que es sometida y, por otra, se abriga en su zona de confort, rodeada de comentarios, ideas y argumentos, con los que se siente cómoda, y que van a reforzar sus posicionamientos distanciándola de otras ideologías y sensibilidades.

Todos ellos son aspectos que se deben seguir de cerca para trazar el porvenir de la política digital a corto-medio plazo, aún en renovación constante para adaptarse a las diferentes posibilidades que brindan las TIC y su apropiación por parte de las personas usuarias, la ciudadanía digital.

\section{REFERENCIAS}

Arcila-Calderón, C., Barbosa-Caro, E., \& Cabezuelo-Lorenzo, F. (2016). Técnicas big data: Análisis de textos a gran escala para la investigación científica y periodística. El Profesional de la Información, 25(4), 623-631. https:/ / bit.ly/3i8w2Hl

Vivat Academia. Revista de Comunicación. 15 septiembre / 15 diciembre 2020, nº 152, 19-48 
Piñeiro-Otero, T. y Martínez Rolán, X.

Para comprender la política digital - principios y acciones

Avalos González, J. M. (2019). La posibilidad tecnopolítica. Activismos contemporáneos y dispositivos para la acción. Los casos de las redes feministas y Rexiste. Comunicación y Sociedad, 16, 1-30. DOI:

http:/ / doi.org/10.32870/cys.v2019i0.7299

Azorín-Richarte, D. (2012). Análisis cibermétrico de los contenidos de Twitter en España (2011). Universidad Politécnica de Valencia. Recuperado de: http://riunet.upv.es/handle/10251/17326.

Barberá, P., \& Rivero, G. (2012). ¿Un tweet, un voto? Desigualdad en la discusión política en Twitter. I Congreso Internacional en Comunicación Politica y Estrategias de Campaña, Madrid. Recuperado de: https:// bit.ly/3g8Ruu9

Bastos, M. T., \& Mercea, D. (2019). The Brexit Botnet and User-Generated Hyperpartisan News. Social Science Computer Review, 37(1), 38-54. https://doi.org/10.1177/0894439317734157

Bejarano Campos, Carolina (2017). Segmentación política estratégica en la era de Internet. ACOP, A Fondo. Recuperado de https://bit.ly/2YBSK2M

Bejerano, P. G. (2013), Cuando los artículos de Wikipedia son pagados. El Diario. Recuperado de https://bit.ly/2NxbKcF

Berrocal Gonzalo, S. (2015). "Politainment: el gran espectáculo político televisivo", ACOP, A Fondo. Recuperado de https:// bit.ly/38kfciS.

Blumler, J.G. \& Kavanagh, D. (2010). The Third Age of Political Communication. Influences and Features, Political Communication, 16(3), 209-230. DOI: $\underline{10.1080 / 105846099198596 .}$

Boulianne, S. (2009). Does internet use affect engagement? A meta-analysis of research. Political Communication, 26 (2), 193-211.

Boyd, D., \& Crawford, K. (2012). Critical questions for big data: Provocations for a cultural, technological, and scholarly phenomenon. Information, communication $\mathcal{E}$ society, 15 (5), 662-679.

Bruce Bimber (2014) Digital Media in the Obama Campaigns of 2008 and 2012: Adaptation to the Personalized Political Communication Environment, Journal of Information Technology $\mathcal{E}$ Politics, 11(2), 130-150, DOI: http:/ / doi.org/10.1080/19331681.2014.895691

Calatrava, A. (2015, mayo 13). Twitter, plataforma clave para movilizar electorado y captar indecisos. Blog de Twitter España. Recuperado de: https://bit.ly/3dAL0Tb

Vivat Academia. Revista de Comunicación. 15 septiembre / 15 diciembre 2020, nº 152, 19-48 
Piñeiro-Otero, T. y Martínez Rolán, X.

Para comprender la política digital - principios y acciones

Calatrava, A. (2016, junio 13). Los votantes españoles consideran que Twitter es la mayor plataforma de influencia política. Blog de Twitter España. Recuperado de: https://bit.ly/3dG4Yf2

Caldevilla, D. (2009). Democracia 2,0: La política se introduce en las redes sociales.Pensar la publicidad, 3(2), 31-48.

Campos-Domínguez, Eva (2017). “Twitter y la comunicación política”. El profesional de la información, 26(5), 785-793.

Carrol, Susan, J. (1999). The Disempowerment of the Gender Gap: Soccer Mons and the 1996 Elections. PS: Political Science and Politics 32 (1), 7-11. doi: http://doi.org/10.2307/420743

Cartes Barrosos, M. J. (2018). El uso de Instagram por los partidos políticos catalanes durante el referéndum del 1 - 0. Revista de Comunicación de la SEECI, 47, 17-36. doi: http:// doi.org/10.15198/ seeci.2018.47.17-36.

Castells, M. (2009). Comunicación y poder. Barcelona: Alianza Editorial.

Castells, M. (2011). Prefacio “Autocomunicació de masas y movimientos sociales en la Era de Internet". Anuari del Conflicte Social, 1. DOI: http://doi.org/10.1344/test.acs.2011.1.6235

Castro Martínez, L. (2012). El marketing político en Estados Unidos: el caso Obama. Norteamérica, Revista Académica, 7(1), 209-222. Recuperado de https:/ / bit.ly/3i2qNcl

Cervi L. \& Roca, N. (2017). La modernización de la campaña electoral para las elecciones generales de España en 2015. ¿Hacia la americanización?. Comunicación y Hombre, 13, 133-150.

Chadwick, A., \& Howard, P. N. (2008). Routledge Handbook of Internet Politics. New York: Routledge. https://doi.org/10.4324/9780203962541

Cihon, P. y Yasseri, T. (2016). A Biased Review of Biases in Twitter Studies on Political Collective Action. Front. Phys. 4 (34). doi: http:/ / doi.org/10.3389/fphy.2016.00034

Coleman, S. (2001). The transformation of citizenship?. En B. Axford \& R. Huggins (Eds.), New media and politics (pp. 109-126). London: SAGE. doi: http:// doi.org/10.4135/9781446218846.n5

Criado, J.I. \& Martínez Fuentes, G. (2010) Blogging político y personalizaciónde la democracia local en España y Portugal. Evidencias presentes y propuestas de futuro. Estudios de Progreso, 56. Madrid: Fundación Alternativas, Recuperado de: https://bit.ly/2UGhYLc

Vivat Academia. Revista de Comunicación. 15 septiembre / 15 diciembre 2020, nº 152, 19-48 
Piñeiro-Otero, T. y Martínez Rolán, X.

Para comprender la política digital - principios y acciones

D'Adamo O. \& García Beadoux, V. (2014). Campañas políticas de bajo coste y Narrativas Políticas Transmedia (NPT). en Más Poder Local, 21, 26-27. Recupearado de: https://bit.ly/2YEoHaJ

Dans, E. (2012, mayo). "Lo que pasa en Facebook se queda en Facebook, en Cinco Días". El Blog de Enrique Dans.Recuperado de: https:// bit.ly/2YAKmAK

Dawkins, R. (2006). The selfish gene. Oxford: Oxford University Press. (V.O. 1976.)

de Aguilera, M. y Casero-Ripollés, A. (2018): ¿Tecnologías para la transformación? Los medios sociales ante el cambio político y social. Icono 14, 16(1), 1-21. doi: https://doi.org/10.7195/ri14.v16i1.1162

Del-Fresno-García, M. (2014). Haciendo visible lo invisible: visualización de la estructura de las relaciones en red en Twitter por medio del análisis de redes sociales. El profesional de la información, 23(3), 246-252. DOI: https://doi.org/10.3145/epi.2014.may.04

Dena, C. (2008). Emerging Participatory Culture Practices: Player-created Tiers in Alternate Reality Games. Convergence. The International Journal of Research into New Media Technologies, 14(1), 41-57. doi: http:// doi.org/d5j7wh

Enguix Oliver, S.(2015) Periodismo especializado y especialización política. Mediaciones Sociales, 14, 103-128.

Fernández-Quijada, D., \& Ramos-Serrano, M. (2014). Tecnologías de la persuasión: Uso de las TIC en publicidad y relaciones públicas. Barcelona: UOC.

Gallerdo-Paúls, B. \& Enguix Oliver, S. (2016). Pseudopolítica: el discurso político en las redes sociales. València: Universitat de València

González, J.L. (2010). La base electoral de Obama, redes sociales virtuales y reales: los casos de generation engage y moms for Obama. Revista Mediterránea de comunicación, 1(1), 25-35. doi: https://doi.org/10.14198/MEDCOM2010.1.1.02

Gorodnichenko, Y., Pham, T., \& Talavera, O. (2018). Social Media, Sentiment and Public Opinions: Evidence from \#Brexit and \#USElection (Working Paper N. ${ }^{\circ}$ 24631; Working Paper Series). National Bureau of Economic Research. https://doi.org/10.3386/w24631

Grasseger, Hannes y Krogerus, Mikael (2017). The Data That Turned the World Upside Down. Stanford. Public Policy Program. Recuperado de: https://stanford.io/2BfUyFV

Grinberg, N., Joseph, K., Friedland, L., Swire-Thompson, B., \& Lazer, D. (2019). Fake news on Twitter during the 2016 U.S. presidential election. Science, 363(6425), 374378. https://doi.org/10.1126/science.aau2706

Vivat Academia. Revista de Comunicación. 15 septiembre / 15 diciembre 2020, nº 152, 19-48 
Piñeiro-Otero, T. y Martínez Rolán, X.

Para comprender la política digital - principios y acciones

Gutiérrez-Rubí, A. (2011). La política vigilada. La comunicación política en la era de 'Wikileaks'. Barcelona: UOC.

Gutiérrez-Rubí, A. (2014). Tecnopolítica. El uso y la concepción de las nuevas herramientas tecnológicas para la comunicación, la organización y la acción política colectivas. Barcelona: Gutiérrez-Rubí. Recuperado de: https://bit.ly/2VpJTPI

Gutierrez-Rubí, A. (2016, noviembre 2). Bots para la comunicación política. Antoni Gutiérrez-Rubí. Recuperado de: https://bit.ly/3icoMdM

Gutiérrez-Rubí (2015). La transformación digital y móvil de la comunicación política. Madrid: Fundación Telefónica y Ariel. IPMARK. Recuperado de https://bit.ly/3g1bcry

Guzmán, F., Paswan, A.K. y Van Steenburg, E. (2015). Self-referencing and political candidate brands: A congruency perspective. Journal of Political Marketing, 14(1-2), 175-199.

Hallin, D. C. (1992). Sound Bites News. Television Coverage of Elections, 1968-1988. Journal of Communication, 52(2), http://dx.doi.org/10.1111/j.14602466.1992.tb00775.x

Harlow, S., \& Guo, L. (2014). Will the Revolution be Tweeted or Facebooked? Using Digital Communication Tools in Immigrant Activism. Journal of Computer-Mediated Communication, 19(3), 463-478. doi: https:// doi.org/10.1111/jcc4.12062

Hedges, C. (2010). Celebrity Culture and the Obama Brand, Tikkun, 25(1), 33-72.

Hernando, A. \& Paramio, G. (2019). Dimensiones interpersonales e hiperpersonales de la comunicación digital: identidades, influencia social y acción colectiva. En Romero Rodríguez, L.M. \& Rivera Rogel D.E. (Coords.), La comunicación Actualidad, retos y prospectivas (pp. 149-170). Naucalpan de Juárez: Pearson Educación.

Hidalgo, C. (2014), “El community manager político”, en Herrero, J.C. \& Römer Pieretti, M. (Coords.) Comunicación en campaña. Dirección de campañas electorales y marketing político. Madrid: Pearson

Howard, P. N., \& Kollanyi, B. (2016). Bots, \#Strongerin, and \#Brexit: Computational Propaganda During the UK-EU Referendum (SSRN Scholarly Paper ID 2798311). Social Science Research Network. https:// doi.org/10.2139/ssrn.2798311

Huberman, B., Romero, D. M., \& Wu, F. (2008). Social networks that matter: Twitter under the microscope. First Monday, 14(1). http://dx.doi.org/10.5210/fm.v14i1.2317 
Piñeiro-Otero, T. y Martínez Rolán, X.

Para comprender la política digital - principios y acciones

Isaak, J., \& Hanna, M. J. (2018). User data privacy: Facebook, Cambridge Analytica, and privacy protection. Computer, 51(8), 56-59.

Islas, O. (2015). La ecología de los medios: metadisciplina compleja y sistémica. Palabra clave, 18 (4), 1057-1083. DOI: https:// doi.org/10.5294/pacla.2015.18.4.5

Java, A., Song, X., Finin, T., \& Tseng, B. (2007). Why we twitter: Understanding microblogging usage and communities. Joint Ninth WebKDD and First SNA-KDD 2007 Workshop on Web Mining and Social Network Analysis, 56-65. https://doi.org/10.1145/1348549.1348556

Jeffares, Stephan (2014). Interpreting Hashtag Politics. Policy Ideas in an Era of Social Media. Nueva York: Palgrave Macmillan

Jenkins, H. (2008). Convergence Culture. La cultura de la convergencia de los medios de comunicación. Barcelona: Paidós.

Justel, M. (1992). El líder como factor de decisión y explicación de voto. Barcelona: Institut de Ciències Polítiques i Socials, Colección Working Paper, 51/92.

Kiyohara, S., Maeshima, K., \& Owen, D. (2017). Internet Election Campaigns in the United States, Japan, South Korea, and Taiwan. Hampshire: Springer.

Kranzberg, M. (1986). Technology and History: «Kranzberg's Laws». Technology and Culture, 27(3), 544-560. http:// doi.org/10.2307/3105385

Krishnamurthy, B., Gill, P., \& Arlitt, M. (2008). A Few Chirps About Twitter. Proceedings of the First Workshop on Online Social Networks, 19-24. https:/ / doi.org/10.1145/1397735.1397741

Kruikemeier, S. (2014). How political candidates use Twitter and the impact on votes. Computers in Human Behavior, 34, 131-139.

Lalancette, M., \& Raynauld, V. (2019). The power of political image: Justin Trudeau, Instagram, and celebrity politics. American Behavioral Scientist, 63(7), 888-924.

Levy, P. (2004). Inteligencia colectiva: por una antropología del ciberespacio. Recuperado de: https://bit.ly/2cqGucY

Lindon, D. (1976). Marketing politique et social. Paris: Dalloz.

Loomis, B.A. (2004). The never ending story: campaigns without elections. En N. Ornstein \& T. Mann (Eds.) The permanent campaign and its future (pp. 162-184). Washington D.C American Enterprise Institute. 
Piñeiro-Otero, T. y Martínez Rolán, X.

Para comprender la política digital - principios y acciones

López-Meri, A., Marcos-García, S. \& Casero-Ripollés, A. (2017). What do Politicians do on Twitter? Functions and Communication Strategies in the Spanish Electoral Campaing of 2016, El profesional de la Información, 26(5), 795-804.

Lys, I. (2019). Data in Politics: an overview. Medium Data Series. Recuperado de: https://bit.ly/2BFq2VP

Marland, A. (2012). Political photography, journalism, and framing in the digital age: The management of visual media by the Prime Minister of Canada. The international journal of politics, 17 (2), 214-233. DOI: http:// doi.org/10.1177/1940161211433838.

Marshall, P.D. (1997). Celebrity and power: Fame in Contemporary Culture. Minneapolis: University of Minnesota Press.

Martínez-Rolán, X., \& Piñero-Otero, T. (2016). Los memes en el discurso de los partidos políticos en Twitter: análisis del Debate sobre el Estado de la Nación de 2015. Communication \& Society, 29(1), 145-160.

Martínez-Rolán, X., \& Piñero-Otero, T. (2017). Lazos invisibles de la comunicación política. Comunidades de partidos políticos en Twitter en unas elecciones municipales. El profesional de la información, 26(5), 859-870. DOI: http://doi.org/10.3145/epi.2017.sep.08

Martínez-Rolán, X., Piñeiro-Otero, T., \& Dafonte-Gómez, A. (2014). Intoxicadores en redes sociales. Astroturfing, una conceptualización en el ámbito de las redes sociales. En El nuevo diálogo social: organizaciones, públicos y ciudadanos (pp. 207-218). Valencia: Campgrafic.

Martínez Rolan, X. (2018). La actividad de los partidos políticos españoles en facebook 2014-2018. La tiranía del algoritmo. Revista de Comunicación de la SEECI, 47, 143-155. doi: http://doi.org/10.15198/seeci.2018.47.143-155.

Martínez Rolán, X. \& Piñeiro Otero, T. (2017). El uso de los memes en la conversación política 2.0. Una aproximación a una movilización efímera. Prisma Social, 18. 55-84.

Martínez Rolán, Xabier (2014). Intoxicación en redes sociales. Una propuesta de clasificación de técnicas de astroturfing. En Gonzálvez Vallés, JE y Valderrama Santomé, M (Eds.) Comunicación actual: redes sociales y lo 2.0 y 3.0 (pp. 377-390). Basauri: Ed. McGraw Hill Iberoamericana.

Matud Juristo, A. (2009). Política 2.0. algo más que internet. Nueva Revista de Política, Cultura y Arte, 121, 46-49.

Mazzoleni, G. \& Schulz. W. (2010). Mediatization of politics. A challenge for democracy? Political Communication, 16(3), 247-261. DOI: https://doi.org/10.1080/105846099198613.

Vivat Academia. Revista de Comunicación. 15 septiembre / 15 diciembre 2020, nº 152, 19-48 
Piñeiro-Otero, T. y Martínez Rolán, X.

Para comprender la política digital - principios y acciones

McKelvey, K. R., \& Menczer, F. (2013). Truthy: Enabling the study of online social networks. Proceedings of the 2013 conference on Computer supported cooperative work companion, 23-26. https://doi.org/10.1145/2441955.2441962

Miller, W. (2013). We can't all Be Obama: The use of new media in modern political campaigns, Journal of Political Marketing, 12(4), 326-347.

Murphy, M.; Barton, J. (2014). From a sea of data to actionable insights: Big data and what it means for lawyers". Intellectual Property \& Technology Law Journal, 26(3), 8-17.

Needham, C. (2005). Brand Leaders: Clinton, Blair and the Limitations of the Permanent Campaign. Political Studies, 53(2), 343-361. https:// doi.org/10.1111/j.1467-9248.2005.00532.x

Negro, I. (2016). Los partidos políticos españoles como marcas: análisis de la campaña para las eleccione generales de 2015. M.F. Litzler, J. García Laborda y C. Tejedor Martínez (Eds.) Beyond the universe of languages for Specific Purposes: The 21st century perspective (pp. 89-94). Madrid: Universidad de Alcalá Servicio de Publicaciones.

Norris, P. (2000). A virtuous circle: political communications in Post-Infustrial Societies. Nueva York: Cambridge University Press.

Norris, P. (2003). Preaching to the Converted?: Pluralism, Participation and Party Websites. Party Politics, 9(1), 21-45. https:// doi.org/10.1177/135406880391003

Norris, P. (2004). The evolution of election campaigns: Eroding political engagement?. Conference on Political Communications in the 21st Century. University of Otago, New Zeland. Recuperado de: https:/ / bit.ly/2Y01IcB

Oliva, M., Pérez-Latorre, Ó., \& Besalú, R. (2015). Celebrificación del candidato. Cultura de la fama, marketing electoral y construcción de la imagen pública del político. Arbor, 191 (775), 270. https://doi.org/10.3989/arbor.2015.775n5009

O'Reilly, T. (2004). What Is Web 2.0._Recuperado de: https:// bit.ly/2kBjFcA

Padró-Solanet, A. y Cardenal, A. S. (2008). Partidos y política en Internet: Un análisis de los websites de los partidos catalanes. Revista de Internet, Derecho y Política, 6, 4664.

Paré, D.J. \& Berger, F. (2008). Political marketing Canadian style? The Conservative Party and the 2006 federal election. Canadian Journal of Communication, 33, 39-63. DOI: http:// doi.org/10.22230/cjc.2008v33n1a1928.

Parisier, E. (2011, marzo 22). Eli Pariser: Cuidado con la «burbuja de filtros» en la red. Recuperado de: https:/ / bit.ly/2YGcOBo

Vivat Academia. Revista de Comunicación. 15 septiembre / 15 diciembre 2020, nº 152, 19-48 
Piñeiro-Otero, T. y Martínez Rolán, X.

Para comprender la política digital - principios y acciones

Parker, B.T. (2012). Candidate brand equity valuation: A comparison of U.S. presidential candidates during the 2008 primary election campaign. Journal of political marketing, 11, (3), pp. 208-230.

Peña-López, I., Congosto, M., \& Aragón, P. (2014). Spanish Indignados and the evolution of the 15M movement on Twitter: Towards networked para-institutions. $\begin{array}{llll}\text { Journal of Spanish Cultural Studies, 15(1-2), } & \text { 189-216. }\end{array}$ https://doi.org/10.1080/14636204.2014.931678

Peris Vidal, M. (2018). El tratamiento periodístico del partido político Podemos en El País y Público: un análisis desde la teoría del framing. Vivat Academia. Revista de Comunicación, 143, 111-134. doi: http://doi.org/10.15178/va.2018.143.111-134

Piñeiro-Otero, T., \& Martínez-Rolán, X. (2013). Presencia, uso e influencia de los diputados del Parlamento de Galicia en Twitter. Revista de Comunicación de la SEECI, 0(32), 106-126. https:/ / doi.org/10.15198/ seeci.2013.32.106-126

Piñeiro-Otero, T., \& Martínez-Rolán, X. (2016). Los memes en el activismo feminista en la Red. \#ViajoSola como ejemplo de movilización transnacional. Cuadernos.info, 0(39), 17-37. doi: http://dx.doi.org/10.7764/cdi.39.1040

Piñeiro-Otero, T. \& Martínez-Rolán, X. (2019). Automedicaicón como Estrategia de Comunicación para el ciberactivismo. Una perspectiva desde el activismo feminista. En: L. Lucena Ito \& P. Melani Rocha (Org.), Transformações do Jornalismo na Nova Ecologia dos Meios (pp.219-212). Aveiro: Ría Editora.

Quevedo-Redondo, R., \& Portalés-Oliva, M. (2017). Imagen y comunicación política en Instagram. Celebrificación de los candidatos a la presidencia del Gobierno. El Profesional de la Información, 26(5), 916-927. https://doi.org/10.3145/epi.2017.sep.13

Re, F. A. (2014). La política transmediática: nuevas formas de participación ciudadana. La trama de la comunicación, 18(1), 33-51.

Rey Lenon, F. (1995). Marketing político, ¿hacer pensar o hacer soñar? Comunicación y Sociedad, 8 (2), pp. 173-184.

Rodríguez, D. (2013). Memecracia: Los virales que nos gobiernan. Barcelona: Gestión 2000.

Rodríguez-Salcedo, N., y Gómez-Baceiredo, B. (2011), Storytelling y astroturfing, dos nuevas estrategias narrativas de movilización social para superar la crisis. Sphera Pública, 11, 69-91.

Rueda Ortiz, R. (2009). Convergencia tecnológica: síntesis o multiplicidad política y cultural. Signo y pensamiento, 25(54), 114-130.

Vivat Academia. Revista de Comunicación. 15 septiembre / 15 diciembre 2020, nº 152, 19-48 
Piñeiro-Otero, T. y Martínez Rolán, X.

Para comprender la política digital - principios y acciones

Ruiz-del-Olmo, F. J., \& Bustos-Díaz, J. (2016). Del tweet a la fotografía, la evolución de la comunicación política en Twitter hacia la imagen. El caso del debate del estado de la nación en España (2015). Revista Latina de Comunicación Social, 71, 108-123. https:// doi.org/10.4185/RLCS-2016-1086

Saftoiu, R. \& Popescu, C. (2014). Humor as a branding strategy in political discourse. A case studie from Romania. Signos, 47(85), 13-14. DOI: http://doi.org/10.4067/S0718-09342014000200007.

Santibañez, C., (2011). Teoría social y memes. A Parte Rei, Revista de Filosofía, 18. Recuperado de: http:// serbal.pntic.mec.es/ cmunoz11/memes.pdf

SÉGUÉLA, J. (1991). Hollywood lava más blanco. Barcelona: Barcelona Business Books.

Selva-Ruiz, D., \& Caro-Castaño, L. (2017). Uso de Instagram como medio de comunicación política por parte de los diputados españoles: la estrategia de humanización en la "vieja" y la "nueva" política. El profesional de la información, 26(5), 903-915.

Serra, P., \& Gonçalves, G. (2016). Politics and Web 2.0: The Participation Gap. Delaware: Vernon Press.

Serrano, J. C. M., Papakyriakopoulos, O., \& Hegelich, S. (2020). Dancing to the Partisan Beat: A First Analysis of Political Communication on TikTok. 12th ACM Conference on Web Science, 257-266. https://doi.org/10.1145/3394231.3397916

Showalter, A., \& Fleisher, C. S. (2005), "The tools and techniques of public affairs", en Harris, P. \& Fleisher, C. (Eds.) The Handbook of Public Affairs (pp. 109-122). London: Sage.

Small, T. A. (2011). What The Hashtag?: A content analysis of Canadian politics on Twitter. Information, Communication $\mathcal{E}$ Society, 14(6), 872-895. https://doi.org/10.1080/1369118X.2011.554572

Sung-Tae, K. \& Young-hwan, L. (2007). New functions of Internet mediated agendasetting: Agenda-rippling and reversed agenda-setting. Korea Journalism Review, 1(2), 3-29.

Tactical Tech (2018, mayo) Tools of the Influence Industry. Recuperado de: https://ourdataourselves.tacticaltech.org/posts/methods-and-practices/

Tigner, R. (2009). Online Astroturfing and the European Union's unfair commercial Practices Directive. Université libre de Bruxelles (ULB). Recuperado de: https://bit.ly/31mp0c5 
Piñeiro-Otero, T. y Martínez Rolán, X.

Para comprender la política digital - principios y acciones

Toret, J. (2015). Tecnopolítica y 15M: la insurgencia de la multitud co- nectada. En J. M. Valenzuela (Coord.), El sistema es antinosotros. Culturas, movimientos y resistencias juveniles (pp. 185-210). Ciudad de México: Gedisa.

Treré, E. \& Barranquero, A. (2018). Tracing the Roots of Technopolitics: Towards a North-South Dialogue. En F. Sierra \& T. Gravante (Coords.), Networks, Movements and Technopolitics in Latin America. Critical Analysis and Current Challenges (pp. 42-58). Londres: Palgrave Mcmillan.

Valeriani, A., \& Vaccari, C. (2018). Political talk on mobile instant messaging services: A comparative analysis of Germany, Italy, and the UK. Information, Communication $\mathcal{E}$ Society, 21(11), 1715-1731. https://doi.org/10.1080/1369118X.2017.1350730

Van Dijck, J., \& Poell, T. (2013). Understanding Social Media Logic. Media and Communication, 1(1), 2-14.

Van Zoonen, L. (2006). The Personal, the Political and the Popular. A Woman's Guide to Celebrity Politics", European Journal of Cultural Studies, 9 (3), 287-301, http://dx.doi.org/10.1177/1367549406066074

Vázquez Sande, P. (2016). Políticapp: hacia una categorización de las APPs móviles de comunicación política. Fonseca, Journal of Communication, 12, 59-78 doi: http:/ / dx.doi.org/10.14201/fjc2016125978

Villoria, M., \& Jiménez, F. (2012). ¿Cuánta corrupción hay en España? Los problemas metodológicos de la medición de corrupción (2004-2011). Revista de Estudios Políticos, 0(156), 13-47. https:/ / recyt.fecyt.es/index.php/RevEsPol/article/view/40032

We Are Social (2020). Digital 2020 España. Recuperado de: https:// wearesocial.com/es/digital-2020-espana

Westling, M. (2007). Expanding the Public Sphere: The impact of Facebook on Political Communication. Recuperado de http://goo.gl/T8wJCI.

Winther, S. (2015). On political brands: A systematic review of the literature. Journal of Political Marketing, 16 (2), 118-146.

Wring, D. (1997). Reconciling marketing with political science: Theories of political marketing. Journal of Marketing Management, 13, 651-663.

Zamora-Medina, R.; Losada-Díaz, J.C.; Vázquez-Sande, P. (2020). A taxonomy design for mobile applications in the Spanish political communication context. El Profesional de la información, 29(3) https://doi.org/10.3145/epi.2020.may.27

Zavattaro, S.M. (2010). Brand Obama. The Implications of a Branded President. Administrative Theory and Praxis, 32, 123-128.

Vivat Academia. Revista de Comunicación. 15 septiembre / 15 diciembre 2020, nº 152, 19-48 
Zúñiga, H. G. de, Barnidge, M., \& Scherman, A. (2017). Social Media Social Capital, Offline Social Capital, and Citizenship: Exploring Asymmetrical Social Capital Effects. Political Communication, 34(1), 44-68. https://doi.org/10.1080/10584609.2016.1227000

\section{AUTOR/ES:}

\section{Teresa Piñeiro-Otero:}

Doctora en Comunicación por la Universidade de Vigo y profesora en el Grado en Comunicación Audiovisual de la Universidade da Coruña. Ha orientado su investigación hacia las nuevas manifestaciones comunicativas especialmente en el ámbito del sonido, las estrategias multimedia o las narrativas transmedia. En esta línea es autora de numerosas contribuciones en revistas y editoriales de impacto. Recientemente ha publicado Sonidos que cuentan. La ambientación sonora audiovisual (Editorial UOC).

teresa.pineiro@udc.gal

Orcid ID: https:// orcid.org/0000-0001-6414-2700

Google Scholar: https://scholar.google.com/citations?user=4hOLIbUAAAAI\&hl=es

ResearchGate: https://www.researchgate.net/profile/Teresa_Pineiro-Otero

Academia.edu: https://coruna.academia.edu/TeresaPi\%C3\%B1eiro

\section{Xabier Martínez-Rolán:}

Doctor en Comunicación por la Universidade de Vigo, premio extraordinario de doctorado y profesor en la Facultad de Ciencias Sociales y de la Comunicación en dicha universidad, donde coordina el Máster en Comunicación en Medios Sociales y Creación de Contenidos Digitales. Sus líneas de investigación se centran en el estudio de comunidades virtuales, uso y apropiación de redes sociales y nuevos formatos publicitarios, y fórmulas comunicativas en nuevos medios. Recientemente ha publicado Diseño de páginas web: Wordpress para todos los públicos (Editorial UOC).

xabier.rolan@uvigo.gal

Orcid ID: https:// orcid.org/0000-0002-7631-2292

Google Scholar: https://scholar.google.es/citations?user=6U99DAQAAAAJ\&hl=es

ResearchGate: https://www.researchgate.net/profile/Xabier_Martinez-Rolan

Academia.edu: https://uvigo.academia.edu/XabierRolan 